\title{
Elastic-plastic Time History Analysis on the Super-high Business-living Building in Hefei
}

\author{
Kewei DING \\ School of Civil Engineering \\ Key Laboratory of Building Structure and Underground \\ Engineering of Anhui Province \\ Anhui Jianzhu University \\ Hefei, China \\ e-mail: dingkw@ahjzu.edu.cn
}

\author{
Chen LI \\ School of Civil Engineering \\ Key Laboratory of Building Structure and Underground \\ Engineering of Anhui Province \\ Anhui Jianzhu University \\ Hefei, China \\ e-mail: 375082599@qq.com
}

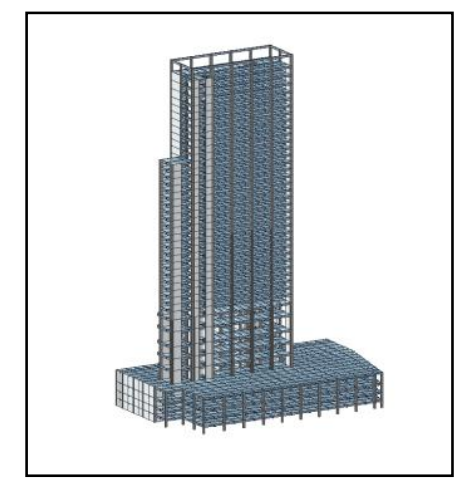

Figure 2. Structural model diagram

\section{DyNAMIC ElaStic-PLASTIC ANALYSIS MODEL AND TIME HISTORY ANALYSIS}

The elastic-plastic time history analysis method is based on the elastic-plastic vibration system of the design structure. Based on the existing detailed data of the seismic wave, the elastic-plastic time history method is applied to the ground motion, and the iterated integral is obtained step by step. Solving the deformation and internal forces with the change in the whole process when the ground acceleration in the course of temporal variation [1]. Time history analysis method is also called direct dynamic method, also can be called elastic-plastic direct analysis method. In mathematics, it is also known as step-by-step integration method. It is a relatively accurate and reliable analysis method for elasticplastic analysis of finite element simulation. This method can obtain the quantitative performance index of the structure under rare earthquakes and it can qualitatively analyze its structure. At the same time, it can be obtained the real seismic response of the structure at all time [2].

By using the dynamic elastic-plastic analysis platform of finite element software MIDAS / Building in this paper, the 42-story super high-rise business-living building was simulated with the finite element software under the condition of rare earthquakes. Then make the dynamic elastic-plastic time history analysis, main to analyze the seismic performance indicators and damage patterns. 


\section{A. Mechanical Model}

Reinforced concrete unit and elastic-plastic damage model of concrete are given in the MIDAS / Building .The elastic-plastic damage model of concrete is applied to the finite element analysis of reinforced concrete structures. For the one-dimensional beams and columns and other components, software using plastic hinge model. Using fiber model for the shear walls. The purpose is to reduce the computational workload. For the beams, columns, shear walls and other components, read into the actual layout of the steel structure of the construction drawing as a way to determine the simulation of the steel reinforcement configuration.

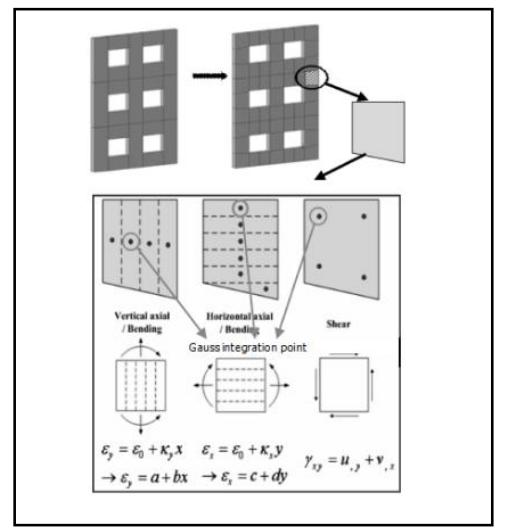

Figure 3. Wall fiber model

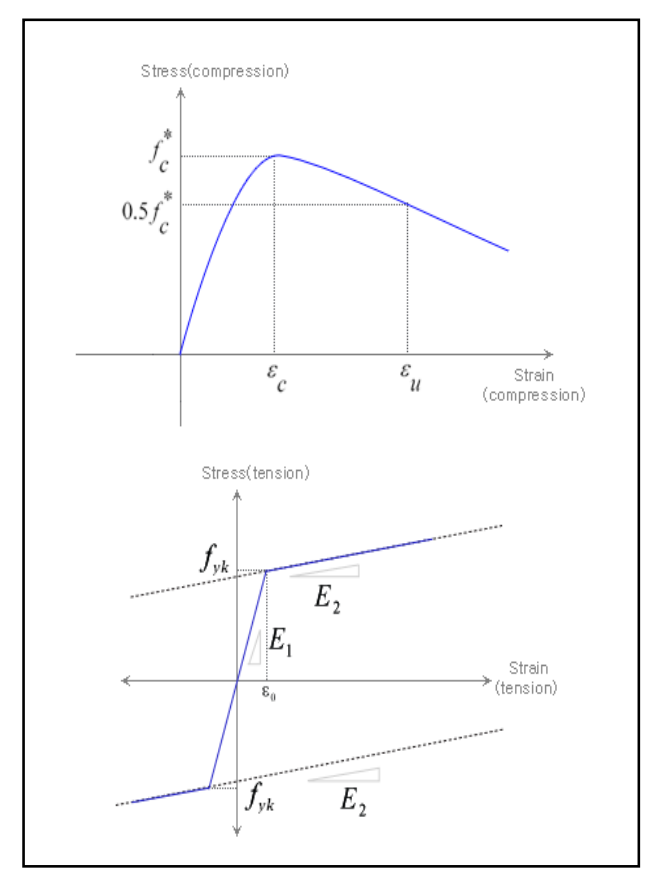

Figure 4. Construction drawing of wall fiber and steel

The wall fiber model is shown in Fig.3. Two fiber models are available when setting the parameters of concrete shear walls in the software: the constitutive model commonly used in the Japanese concrete code, and the relationship of uniaxial stress-strain. The project case is to set the concrete material using the constitutive model of Appendix C which in the "Code for Design of Reinforced Concrete Structures" (GB50010--2010) [3], reinforced material using bilinear constitutive mode, for Fig.4. The PMrelated plastic hinge model is adopted for columns. The beams adopt the MM plastic hinge model and adopt the modified Takeda trilinear model as the hinge characteristic value of the beam and column [4].

\section{B. Calculation Conditions}

In the MIDAS / Building software, we check "use initial load: $1 \times$ DL (dead load) $+0.5 \times$ LL (live load)" because the actual seismic load of engineering structure is based on dead load and live load. So this dynamic time history analysis will use this load setting as the initial load of its initial step.

In accordance with the relevant norms and safety evaluation report, we select three seismic waves: an artificial seismic wave and two natural seismic waves, and select the two-way seismic to input parameters. In addition, a set of elastic calculation under frequent earthquakes is selected as a supplementary reference [5].

The size of the elastic-plastic model is: the number of nodes is 10858 , the number of elements is 13684 , the number of the main nodes is 40383 and the number of slave nodes is 15026 , the number of beam hinges is 2125 for FEMA hinges (RC), the number of column hinges is 800 for FEMA hinges (SRC + RC), the number of wall units is 1356 (fiber model).

\section{Results of Elastic Calculation and Evaluation}

Architectural structure design software (YJK) is used to carry out elastic calculation of the super high-rise structure under the frequent earthquake state. The performance of each index is content with currently state criterion. The integral calculation results are shown in Table I .

D. Selection of Seismic Wave

TABLE I. INTEGRAL CALCULATION RESULTS

\begin{tabular}{|c|c|}
\hline Calculate parameter & Results \\
\hline The number of modes is calculated & 30 \\
\hline $\mathrm{T} 1(\mathrm{X}) / \mathrm{s}$ & 3.8265 \\
\hline $\mathrm{T} 2(\mathrm{Y}) / \mathrm{s}$ & 3.4978 \\
\hline $\mathrm{T} 3$ (torsion)/s & 2.7145 \\
\hline $\mathrm{T} 3 / \mathrm{T} 1$ & 0.71 \\
\hline Bottom shear-weight ratio (X)/\% & 1.52 \\
\hline Bottom shear-weight ratio (Y)/\% & 1.60 \\
\hline Earthquake maximum inter-story drift (X) & $1 / 1153$ \\
\hline Earthquake maximum inter-story drift (Y) & $1 / 1136$ \\
\hline $\begin{array}{c}\text { The maximum axial compression ratio of } \\
\text { bottom shear wall }\end{array}$ & 0.48 \\
\hline $\begin{array}{c}\text { The maximum axial compression ratio of } \\
\text { bottom frame column }\end{array}$ & 0.59 \\
\hline Modal participating mass ratio (X) & $97.26 \%$ \\
\hline \begin{tabular}{c} 
Modal participating mass ratio (Y) \\
\hline
\end{tabular} & $95.14 \%$ \\
\hline
\end{tabular}


According to the seismic fortification criteria, the site conditions, the period corresponding to the first mode of the building, the natural seismic waves Chi-Chi, Taiwan05_NO_2937; Tg (0.41), Kocaeli, Turkey_NO_1177, Tg $(0.40)$, and Artificial Wave 01, Tg (0.40) which is suitable for the site were selected. The peak value of seismic wave acceleration is $220 \mathrm{gal}$.

\section{E. Analysis of Structural Deformation under Rare Earthquakes}

In rare earthquakes, the maximum inter-story drift ratio of artificial wave 01 in $\mathrm{X}$ directions is $1 / 125$ and $\mathrm{Y}$ directions is $1 / 138$. The maximum inter-story drift ratio of the natural wave Chi-Chi Taiwan-05_NO_2937 in the X directions is $1 / 125$ and $Y$ is $1 / 126$. The natural wave Kocaeli, Turkey_NO_1177 to produce the maximum inter-story drift ratio is $1 / 12 \overline{6}, 1 / 154$ in the $\mathrm{X}, \mathrm{Y}$ direction.

Analysis of Fig.5 shows that the first floor to the fourth floor is underground shopping malls and parking lots, the calculation results are basically controlled within a certain range of specifications. Analysis shows that in the $X$ direction, the two indicators that structural displacement and torsion resistance effects are preferable, But in the $\mathrm{Y}$ direction, the numerical values of the inter-story drift ratio is smaller than those of the $\mathrm{X}$ direction, which indicates that the displacement and torsion resistance effects of the $\mathrm{Y}$ direction are better than those of the $\mathrm{X}$ direction [7].

Respect to the selected three seismic waves from Table II, the average value of the inter-story drift ratio of the $X$ direction is $7 / 880$, where the maximum value is $1 / 125$; the average value of the inter-story drift ratio of the $\mathrm{Y}$ direction is $2 / 277$, where the maximum value is $1 / 126$, and the average values and maximum values of the inter-story drift ratio in both directions meet the requirement of the specification limit of $1 / 100$.

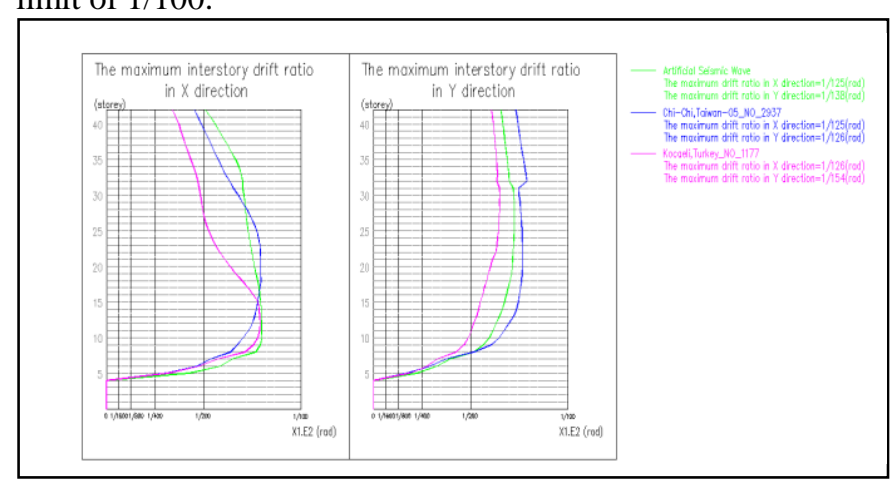

Figure 5. Inter-story drift ratio of three seismic waves

The deformation of the frame hinge is shown in Fig.6, and the deformation of the column hinge is shown in Fig.7, which shows the worst case of the deformation of the frame hinge under Artificial Wave 01. According to the FEMA 356 , the maximum plastic angle of beam in the LS (Life Safety) stage is 0.02 , and the plastic deformation of the beam hinge is 0.01800 from the picture of plastic deformation. The allowable plasticity corner of the column in the LS stage is 0.01 and the maximum plastic angle in IO (Immediately Occupancy) stage is 0.003 . The maximum plastic corner deformation of the column hinges of this structure is 0.00180 [8]. So the beams of the structure are in the LS stage, and the columns are in the IO stage, which all meet the structural design of the sated performance targets.

TABLE II. CALCULATION Results OF SEISMiC Action OF EACH SEISMIC WAVE

\begin{tabular}{|c|c|c|c|c|}
\hline \multirow{2}{*}{ Seismic wave } & \multicolumn{2}{|c|}{$\begin{array}{c}\text { Maximum inter- } \\
\text { story drift }\end{array}$} & \multicolumn{2}{c|}{ Base shear (KN) } \\
\cline { 2 - 5 } & $\begin{array}{c}\boldsymbol{X} \\
\text { direction }\end{array}$ & $\begin{array}{c}\boldsymbol{Y} \\
\text { direction }\end{array}$ & $\begin{array}{c}\boldsymbol{X} \\
\text { direction }\end{array}$ & $\begin{array}{c}\boldsymbol{Y} \\
\text { direction }\end{array}$ \\
\hline Artificial wave 01 & $1 / 125$ & $1 / 138$ & 30249 & 28393 \\
\hline $\begin{array}{c}\text { Chi-Chi,Taiwan- } \\
\text { 05_NO_2937,Tg(0.41) }\end{array}$ & $1 / 125$ & $1 / 126$ & 32736 & 36683 \\
\hline $\begin{array}{c}\text { Kocaeli,Turkey_NO_1 } \\
\text { 177,Tg(0.40) }\end{array}$ & $1 / 126$ & $1 / 154$ & 29334 & 34473 \\
\hline
\end{tabular}

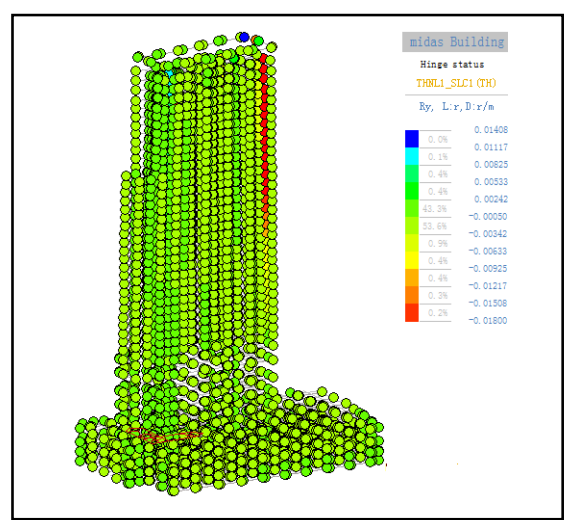

Figure 6. Deformation of frame beam hinges

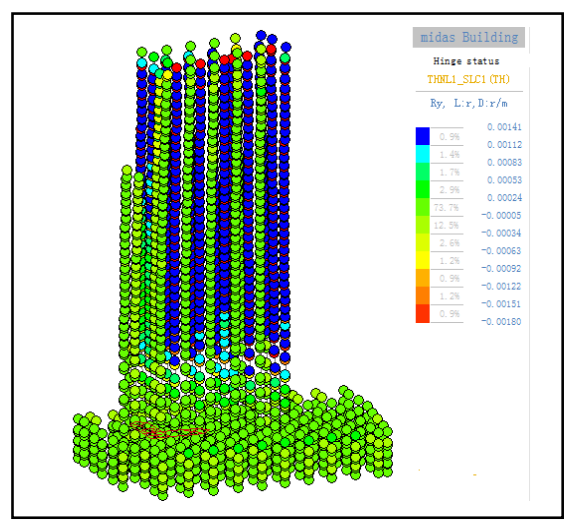

Figure 7. Deformation of frame column hinges

Compression and tension damage of frame column and the coupling beam and the frame beam, shear wall under the earthquake wave as shown from Fig.8 to Fig.10. Under the action of the rare earthquakes, the frame beam and coupling beam most come into the plastic, The plastic performance of coupling beam fully developed, which play a very good energy-consuming role, part of the shear wall moderate damage and individual shear wall appears more serious damage, most of the framework of the column is basically 
intact. All this achieve the design goals of two defensive lines.

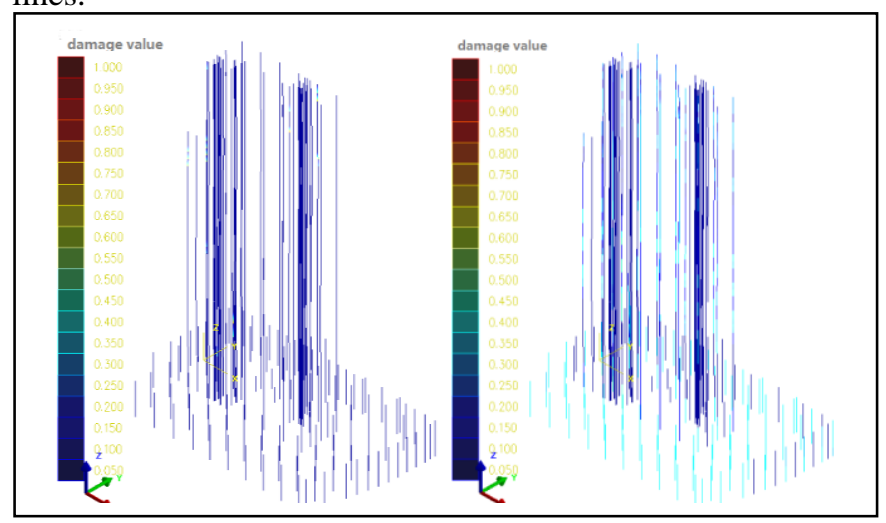

Figure 8. Compression damage and tension damage of frame columns

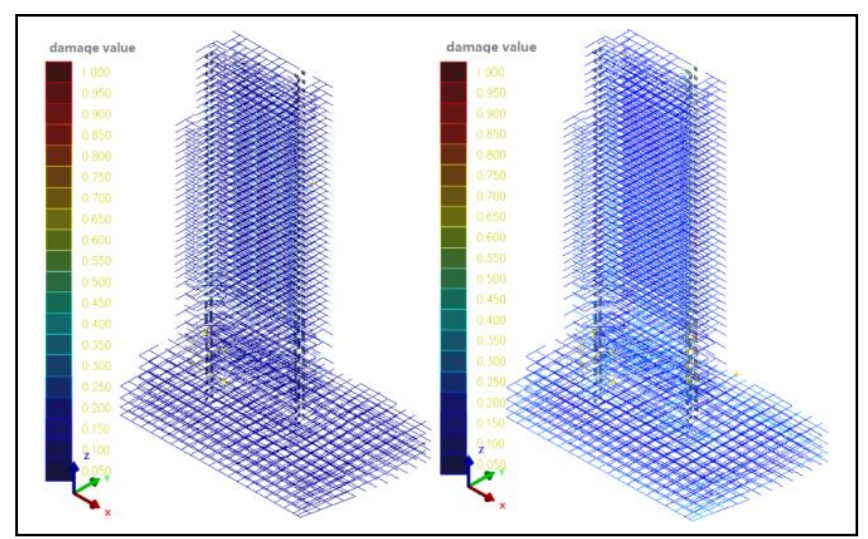

Figure 9. Compression damage and tension damage of coupling beams and frame beams

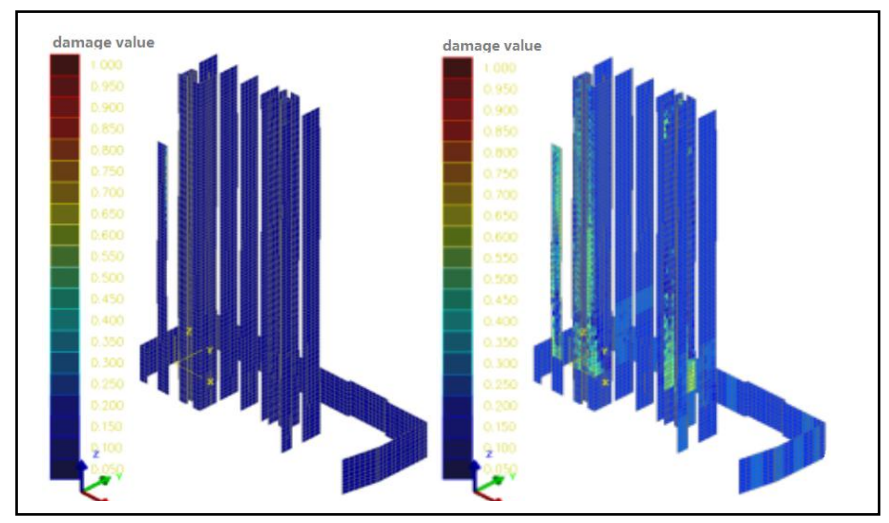

Figure 10. Compression damage and tension damage of shear walls

\section{CONCLUSION}

- According to the above results of dynamic elasticplastic time-history analysis, the inter-story drift ratio of the structure in rare earthquakes is less than $1 / 100$, which meets the requirements of the criterion, and has a certain margin, the structural seismic fortification standard that "no collapse under strong earthquake" can be achieved.

- Under the action of rare earthquake, the hinge sequence of each component is basically: the first coupling beam yield, the second part of the frame beam yield, and finally part of the vertical members present hinges. The failure mechanism and elastic plastic response of the structure under the action of rare earthquake are satisfied with the concept of structural seismic and the relevant design requirements.

\section{ACKNOWLEDGMENT}

This project supported by Anhui Provincial Science and Technology Research Project Funding through grant No.1501041133, and Anhui Provincial Universities Natural Science Research Project No. KJ2015A046.

\section{REFERENCES}

[1] WANG Xiao-bing, The Comparative Study of Nonlinear Static and Dynamic Analysis for Mega-frame Structure. Central south University, 2010.

[2] LIU Liang-lin, WANG Quan-feng and SHEN Zhang-chun, "The selection method of seismic wave based on elastic total input energy," Journal of Huaqiao University (Natural Science), 2009, pp. 191-194.

[3] GB50010-2010 Code for Design of Concrete Structures. BeiJing: China Architecture \& Building Press, 2010.

[4] YANG Ji-chong, HU Hai-tao, HUANU Xin, LI Jianfeng and WAND Yang, "Elasto-plastic time history analysis of one transfinite high-rise structure," Journal of Qingdao Technological University, 2015, pp. 20-26.

[5] GB50011-2010 Code for Seismic Design of Buildings. BeiJing: China Architecture \& Building Press, 2010.

[6] YANG Zhi-yong, HUANG Ji-feng and SHAO Hong, "Discussion on linear and nonlinear time history and analysis method," Journal of Building Structures, 2009, pp. 213-217.

[7] LUO Jian-feng, Comparative Research on the Nonlinear Static and Dynamic Structural Analysis of RC Frame. TongJi University, 2007.

[8] ZHANG Xue-feng, "Elasto-plastic time history analysis of Suzhou Zhongrun Square main building," Building Structure, vol. 04, 2011, pp. 64-68.

[9] ZHAO Yu-xing, Super High-rise Building under Strong Earthquake Dynamic Elasto-plastic Time-history Analysis. TianJin University, 2014.

[10] WANG Wei, Seismic Performance Study of High-rise Concrete Structure Based on the Elastic-plastic Analysis Method. Hefei University of Technology, 2013. 